Irish Math. Soc. Bulletin

Number 69, Summer 2012, 60-62

ISSN 0791-5578

\title{
Persi Diaconis and Ron Graham: Magical Mathematics, Princeton University Press, 2012, ISBN:978-0-691-15164-9
}

\author{
REVIEWED BY FIACRE Ó CAIRBRE
}

The authors have produced an invaluable contribution to the fascinating relationship between magic and mathematics. There is an engaging account of the history and characters behind the pieces of magic. The authors delve into some non-trivial mathematics behind the tricks and also give other applications of the relevant mathematics. This attractively produced book provides an enlightening insight into the crossover between mathematics and magic. Step by step instructions are given for each trick and so after reading it you may be able to impress your family and friends with some stunning magic. Both authors are professional mathematicians and one is a professional magician while the other is a professional juggler.

The authors exhibit a lifelong passion, enthusiasm and deep knowledge for magic and mathematics and this is an ideal combination for producing a great read. As a thirteen year old, one of the authors was a regular at the world famous Tannen's Magic Emporium in New York's Times Square. The shop was like a wonderland for a young boy interested in magic. An endearing account of some of the other regulars at Tannen's is provided. For example, one regular is described as follows: "There's Manny Kraut, a huge man whose fat hands somehow make the most beautiful, delicate card tricks".

One of the earliest tricks discussed goes back to Fibonacci's famous book, Liber Abaci, which appeared in 1202. The first serious magic books (two of them coincidentally in the same year) appeared in 1584. The current state of magic today is very vibrant and is described as "a very active whirlpool". The authors say "there are a handful of inventors who are repeatedly brilliant" and seven of them are discussed in the book. It's quite a diverse lot. There is a chicken farmer from Petaluma, a rural free-delivery mailman, a computer

Received on 11-5-2012. 
wizard (or two) and a priest. One was a hobo who lived out of dumpsters.

The book contains a wide diversity of types of tricks including cards, coins, pictures, words, paper folding and chains. My three favourite tricks involve de Bruijn sequences, the Gilbreath Principle and the so called Miracle Divination. A de Bruijn sequence with window length $k$ is a zero/one sequence of length $2^{k}$ such that every $k$ consecutive digits appear just once (going around the corner). For example, 11100010 is a de Bruijn sequence of window length 3. If one has a de Bruijn sequence of window length $k$, then one can perform the trick with $2^{k}$ cards. This is a great trick that should impress any audience. Continuing in the tradition of the magician keeping the details of the trick secret from the audience, I won't give away the details of the trick. I think it's better that one reads the book in order to see the details of the tricks. Some non-card trick applications of de Bruijn sequences and higher dimensional de Bruijn arrays are discussed including robotic vision, industrial cryptography, DNA, protein folding and rhyming patterns in East Indian music. The authors mention some open problems in mathematics concerning higher dimensional de Bruijn arrays. They also give some details about a recently solved problem related to Hamiltonian cycles.

The Gilbreath Principle is named after Norman Gilbreath who was an undergraduate in mathematics when he created an ingenious new card trick that would stun the world of magic. In July 1958, Gilbreath introduced himself in the magic magazine, Linking Ring, as follows: "I have been interested in magic for ten years. I am a math major at UCLA. Being a supporter of the art of magic, I have created over 150 good tricks and many others not so good. Here are a couple I hope you can use". He then gave a brief account of what is now called Gilbreath's First Principle. His new card trick was picked up and varied almost immediately by the magic community. In the January 1959 issue of Linking Ring, card experts Charles Hudson and Edward Marlo wrote "It is not often one runs across a new principle in card magic ... Gilbreath's principle has proved the most popular card effect to appear in the parade for a long time". In a 1966 issue of Linking Ring, Gilbreath, who was now a professional mathematician working for the Rand Corporation, introduced his so called Second Principle, which included new uses for his First Principle and many non-card tricks. 
There is a surprising connection between Gilbreath's Principle and the Mandelbrot set. The authors were informed about this connection by Dennis Sullivan who attributes its proof to the Fields Medallists, John Milnor and William Thurston. This story illustrates that the mathematics behind card tricks may be a lot deeper than one might think. Some other non-magic applications of Gilbreath's Principle are given, including applications to Penrose tiles and designing sorting algorithms for computers.

The Miracle Divination is a coin trick involving three spectators. It has a long history with one version going as far back as Fibonacci's 1202 book, Liber Abaci.

The authors perform their magic to an eclectic audience. For example, in relation to the trick involving de Bruijn sequences above they say: "The trick is one we have performed for drunks in seedy nightclubs, at Hubert's Flea museum and at the banquet for the American Mathematical Society".

This illuminating book was a pleasure to read and I highly recommend it to anybody interested in the mathematics behind some impressive magic.

Fiacre Ó Cairbre is a Senior Lecturer in the Department of Mathematics and Statistics at NUI, Maynooth. His research interests are currently in the three areas of stability theory, mathematics education and the history of mathematics.

Department of Mathematics and Statistics, NUi, Maynooth

E-mail address: fiacre.ocairbre@nuim.ie 